\title{
Investigation of Coastal Hydrogeology Utilizing Geophysical and Geochemical Tools along the Broward County Coast, Florida
}

Open-File Report 2008-1364 

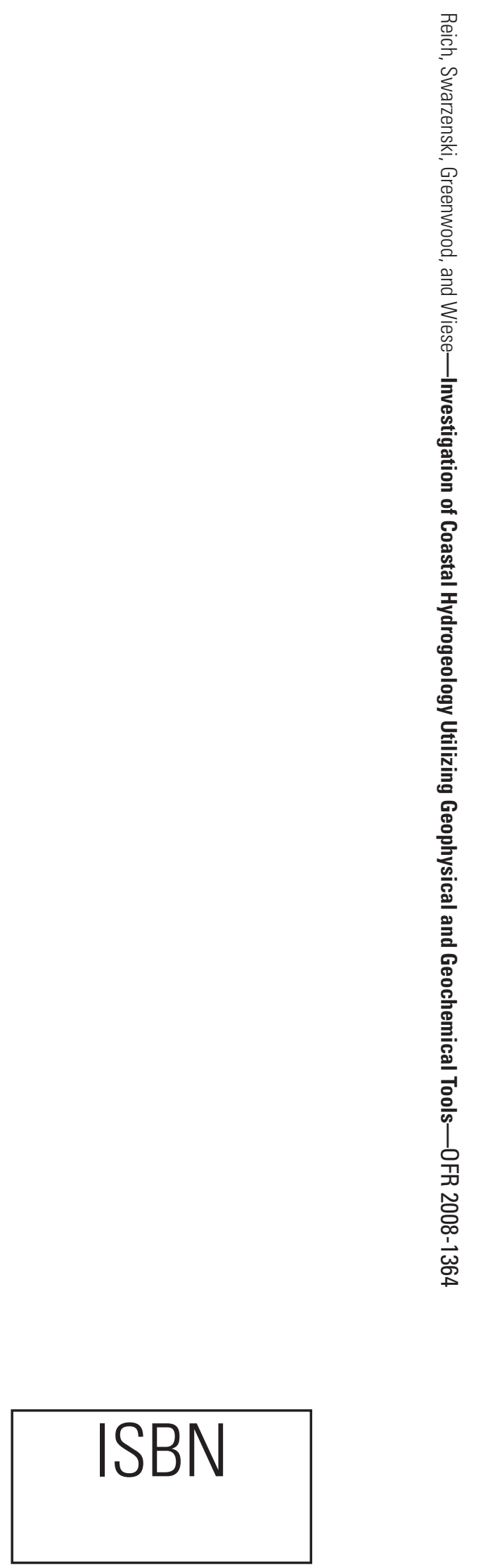